\title{
Spletno nadlegovanje v šolah z vidika spola
}

\author{
Barbara Neža Brečko
}

U

poraba informacijsko-komunikacijske tehnologije (IKT) prinaša $\mathrm{v}$ naše življenje prednosti in koristi, obenem pa se z uporabo IKT pojavljajo tudi slabosti. Ena teh slabosti, ki je v zadnjih letih deležna vse večje pozornosti, je medvrstniško spletno nasilje oziroma spletno nadlegovanje.

Spletno nasilje oziroma spletno nadlegovanje je ena od oblik medvrstniškega nasilja, ki vključuje psihološko nasilje, ustrahovanje, trpinčenje, ogrožanje, žaljenje drugih oseb s pomočjo uporabe informacijsko-komunikacijske tehnologije. Spletno nadlegovanje je tesno povezano z uporabo IKT, hkrati pa različni avtorji ugotavljajo, da je pojav povezan tudi s tako imenovanimi tradicionalnimi oblikami nasilja (npr. z nasiljem, ki se ne dogaja v spletnem okolju). Med obema oblikama nasilja so določene podobnosti, in sicer: obe vrsti nasilja lahko žrtvi povzročita hude posledice, do obeh lahko pride zaradi pomanjkanja nadzora, pogosto pride do nasilja $\mathrm{v}$ šolskem okolju in žrtve pogosto poznajo storilca (Agatston et al., 20I2; Cassidy et al., 20II; Cassidy, Jackson in Brown, 2009; Hinduja in Patchin, 20I2a, 2012b; Kowalski et al., 2012; Tokunaga, 2010).

Spletno nasilje nad ženskami in dekleti je nasilje na podlagi spola, ki se izvaja z elektronsko komunikacijo in internetom. Čeprav lahko spletno nasilje vpliva na ženske in moške, ženske in dekleta doživljajo drugačne in bolj travmatične oblike spletnega nasilja. Obstajajo različne oblike spletnega nasilja nad ženskami in dekleti, na primer spletno zalezovanje, pornografija brez privolitve osebe na slikah (t. i. pornografija iz maščevanja, ang. revenge porn), blatenje in nadlegovanje zaradi spola, zmerjanje $\mathrm{z}$ vlačugo (ang. slut-shaming), neželena pornografija, spolno izsiljevanje 
(sextortion), grožnje s posilstvom in smrtjo, zbiranje informacij o žrtvi in razgaljanje njene zasebnosti na internetu (doxing) (EIGE, 20I7).

Da gre za pereč problem, je pokazala študija FRA (20I2), ki je ugotovila, da je v EU med 5 in I 8 \% žensk, starejših od Is let, ki so že doživele spletno nasilje. EIGE - Evropski inštitut za enakost spolov (20I7) ugotavlja, da vsaka deseta ženska po petnajstem letu doživi spletno nasilje. Med mladostniki je ta delež še višji. S slovensko raziskavo ugotavljamo, da dekleta pogosteje kot fantje doživijo spletno nadlegovanje (Odklikni, 2oı8).

\section{Definicije spletnega nasilja}

Ko obravnavamo spletno nadlegovanje, se soočamo s precejšnjim izzivom, saj pregled literature kaže na pomanjkanje doslednih, standardnih definicij in metodologij za konceptualizacijo in merjenje spletnega nadlegovanja. Kot poudarja tudi Svet Evrope (2018), še vedno ni enotnega izrazoslovja ali tipologije kaznivih dejanj, ki se štejejo za spletno nadlegovanje, mnoge oblike spletnega nadlegovanja so medsebojno povezane, se prekrivajo oziroma so sestavljene iz kombinacije dejanj. Spletno nadlegovanje je pojav, ki ga različni avtorji opisujejo $\mathrm{z}$ različnimi izrazi in definicijami. $\mathrm{V}$ slovenščini imamo z enotnim poimenovanjem še nekoliko večjo težavo, saj že za besedo »cyber« najdemo različne prevode (npr. spletno, kibernetsko, internetno ...).

Izraz »spletno nasilje« (ang. cyberbullying) se je pričel pojavljati $\mathrm{v}$ akademskih člankih in literaturi leta 2003, ko je Bill Belsey vzpostavil spletno stran www.cyberbullying.ca, kjer je obravnaval spletno nasilje v Kanadi (Bauman in Bellmore, 2015). Prva definicija spletnega nasilja se je glasila:

Spletno nasilje vključuje uporabo informacijsko-komunikacijske tehnologije za namerno, ponavljajoče se in sovražno vedenje posameznika ali skupine, s katerim se namerno škodi drugim (Belsey, 2003).

Čeprav gre za pogosto uporabljan izraz, pa je v akademski (pa tudi neakademski) literaturi težko zaslediti soglasje, katera vedenja sodijo v spletno nadlegovanje. Pomanjkanje konsistentnosti in konsenza sicer pripisujejo temu, da gre za relativno nov pojav (Law, Shapka, Hymel, Olson in Waterhouse, 20I2), obenem pa ugotavljamo, da tudi na nekaterih drugih (vsebinskih) področjih, ki vključujejo IKT, pogosto naletimo na težave enotnega poimenovanja.

Število različnih definicij in poimenovanj kaže na hiter razvoj tehnologije v zadnjem desetletju, $z$ razvojem pa se spreminjajo tudi oblike spletnega nasilja. Vrsto različnih definicij najdemo za sam izraz spletno nasilje, hkrati pa je za spletno nasilje oziroma oblike spletnega nasilja v 


\section{uporabi še vrsta drugih izrazov. V Tabeli i predstavljamo le nekaj prime- rov različnih definicij oziroma opisov spletnega nasilja.}

Tabela ı: Definicije spletnega nasilja.

Spletno nasilje je »naklepno in ponavljajoče se povzročanje škode, ki se zgodi preko elektronskega medija $\ll$ (Patchin in Hinduja, 2006: str. 152).

Spletno ustrahovanje je $\gg$ način nasilništva, pri katerem vrstniki uporabljajo elektronske medije za norčevanje, žaljenje, grožnje, nadlegovanje in/ali ustrahovanje vrstnika (Raskauskas in Stoltz, 2007: str. 565).

Spletno nasilje je zasnovano tako, da »osramoti, grozi, poškoduje ali izključi« (Bhat, 2008: str. 58 ).

Spletno nasilje je »oblika agresije, ki se pojavi prek osebnih računalnikov (npr. e-pošte in neposrednih sporočil) ali mobilnih telefonov (npr. besedilnih sporočil) (Wang, Iannotti in Nansel, 2009: str. 369).

»Spletno nasilje je vsako vedenje, ki ga prek elektronskih ali digitalnih medijev izvajajo posamezniki ali skupine, ki večkrat sporočajo sovražna ali agresivna sporočila, katerih namen je povzročiti škodo ali nelagodje drugim « (Tokunaga, 20ıо: str. 278).

Spletno nasilje vključuje »uporabo IKT za podporo namernim, ponavljajočim se in škodljivim dejanjem z namenom povzročanja škode drugim « (Akbulut et al., 20ıо: str. 47).

»Spletno nasilje se zgodi, kadar se internetne aplikacije uporabljajo za sistematično ustrahovanje ali žalitev osebe z namenom, da bi jo ponižale, osramotile ali poškodovale. Podobno kot fizično nasilje tudi spletno nasilje vključuje namerna, ponavljajoča se dejanja in psihično nasilje« (Valkenburg in Peter, 2011: str. 124-125).

Spletno nasilje vključuje » ponavljajočo se uporabo tehnologije za nadlegovanje, poniževanje ali grožnje « (Holladay, 20ıı: str. 4).

»Spletno nasilje je opredeljeno kot namerno dejanje spletnega/digitalnega ustrahovanja, sramotenja ali nadlegovanja (Mark in Ratliffe, 20ıг: str. 92).

Spletno nasilje je sistematična zloraba moči, ki se zgodi z uporabo informacijsko-komunikacijskih tehnologij (IKT) (Slonje et al., 2013: str. 26).

Spletno nasilje je »vsako usmerjeno agresivno vedenje prek elektronskih komunikacijskih tehnologij« (Mehari et al., 2014: str. 400).

Spletno nasilje je »ponavljajoča se nezaželena, škodljiva, nadlegovalna in/ali grozilna interakcija prek elektronskih komunikacijskih medijev« (Rafferty in Vander Ven, 20I4: str. 364).

»Ko rečemo spletno nadlegovan, mislimo na nasilje prek e-pošte, neposrednih sporočil, družbenih medijev, v klepetalnici, na spletnem mestu, v spletni igri ali prek besedilnega sporočila, poslanega na mobilni telefon. Na primer, nekdo, ki pošlje zlobna sporočila drugi osebi v e-pošti ali objavi negativne komentarje ali informacije o tej osebi prek družbenih medijev, kot je Facebook, izvaja spletno nasilje $\ll$ (Whittaker in Kowalski, 20I5: str. I4).

Čeprav se definicije oziroma opisi med seboj nekoliko razlikujejo (gre za opise od leta 2006 dalje), pa lahko ugotovimo, da imajo skupne značilnosti - gre za usmerjene, ponavljajoče se aktivnosti z namenom škoditi drugemu, ki se dogajajo z uporabo IKT.

Pri tem je treba poudariti še naslednje pomembne specifike spletnega nadlegovanja, ki spletno nasilje ločujejo od t. i. tradicionalnega: a) anonimnost, ki jo zagotavlja splet, otežuje kazenski pregon storilcev; b) za izvajanje spletnega nasilja ni treba posebnega znanja oziroma dobrega 
poznavanja tehnologij; c) cenovna dostopnost tehnologije, ki omogoča hitro širjenje (zapisov, slik, posnetkov); d) široko (spletno) občinstvo; e) digitalna stalnost - »internet beleži vse in ničesar ne pozabi «. Karkoli se o določeni osebi objavi na spletu, postane del njene/njegove (spletne) identitete (West, 20I4).

Spletno nasilje torej lahko opredelimo kot vedenje na spletu, ki škodi fizičnemu, psihičnemu ali čustvenemu počutju žrtve. Izvajalec spletnega nasilja kot tudi žrtev le-tega je lahko posameznik ali skupina, zgodi pa se ob uporabi spleta, pametnih telefonov, med igranjem internetnih iger. Čeprav spletno nasilje poteka prek spleta, pa ima vpliv v resničnem svetu in ima resnične posledice. $V$ slovenskem prostoru razumemo, da spletno nasilje vključuje, vendar ni omejeno na: spletno nadlegovanje, grožnje, trpinčenje, izsiljevanje, neželeno pošiljane vsebin s spolno vsebino, zalezovanje, sovražni govor, deljenje slik brez privolitve, snemanje in distribucijo spolnih vsebin.

\section{Spletno nasilje zaradi spola}

Ko govorimo o spletnem nasilju in nadlegovanju zaradi spola, govorimo o različnih oblikah nasilja, ki so posledica neenakosti med spoloma in so usmerjene proti osebi zaradi njenega spola ali spolne usmerjenosti. Tako ženske kot moški doživljajo nasilje zaradi spola, vendar je večina žrtev žensk in deklet (EIGE, 2019).

Med oblikami spletnega nadlegovanja, ki se dogajajo predvsem dekletom, lahko izpostavimo naslednje:

- Posredovanje fotografij/posnetkov brez privolitve (imenovano tudi maščvalna pornografija; ang. revenge porn) To vključuje objavljanje in razširjanje zasebnih fotografij ali videoposnetkov spolne narave za javno poniževanje žrtve. Storilec oz. storilka je pogosto nekdanji partner, ki želi z zlorabo zasebnih posnetkov žrtev osramotiti oziroma jo prisiliti, da razmerja ne konča. Sexting (pošiljanje golih fotografij osebe), neželena pornografija (pošiljanje slik s seksualno vsebino, npr. spolnih organov) - ko moški pošiljajo slike svojih spolnih organov ženskam.

- Spletno nadlegovanje (ang. cyber harassment) - namerno prečkanje meje čustvene ali fizične varnosti, ki običajno vključuje večkratno komunikacijo. Spletno nadlegovanje se nanaša na žaljenje osebe na spletu z neželenimi seksualno eksplicitnimi sporočili, grožnjami z nasiljem ali sovražnim govorom (EIGE, 2019). FRA (2015) spletno nadlegovanje opredeljuje kot prejemanje neželenih, žaljivih, spolno 
nazornih e-poštnih sporočil ali SMS sporočil; žaljenje na spletnih straneh družbenih omrežij ali v internetnih klepetalnicah.

- Sexting - pošiljanje (lastnih) golih fotografij.

- Spletno zalezovanje (ang. cyber stalking) - vohunjenje za žrtvijo, komuniciranje z njo proti njeni volji. Zalezovanje vključuje ponavljajoče se incidente, ki spodkopavajo občutek varnosti in povzročajo stisko, strah ali paniko. Spletno zalezovanje lahko vključuje:

- pošiljanje e-poštnih sporočil, besedilnih sporočil (SMS) ali neposrednih sporočil (ang. instant messaging), ki so žaljiva ali grozilna;

- objavljanje žaljivih komentarjev o žrtvi v socialnih omrežjih na internetu;

- deljenje intimnih fotografij ali videoposnetkov žrtve v socialnih omrežjih na internetu ali preko mobilnih telefonov.

- Sramotenje - zmerjanje z vlačugo (ang. slut shaming) - kritiziranje oseb, zlasti žensk in deklet, ki naj bi kršile pričakovanja/pravila glede vedenja in videza predvsem $\mathrm{v}$ povezavi s spolnostjo

- Zloraba tehnologije $v$ partnerski zvezi (ang. cyber dating abuse $C D A$ ) - uporaba tehnologije za spremljanje in nadzor partnerjevega vedenja; z uporabo gesla partnerja brez dovoljenja za dostop do njegovih e-poštnih računov ali družbenih medijev; namestitev sledilnih naprav ali aplikacij za spremljanje lokacije partnerja; čustveno nasilje in verbalne grožnje z digitalnimi sredstvi med ali po končani zvezi

\section{Obstoječe raziskave - ugotovitve}

Število študij, ki obravnavajo spletno nadlegovanje $\mathrm{z}$ vidika spola med mladostniki, je še vedno relativno omejeno. Starejše študije (npr. Slonje in Smith, 2008) niso našle posebne povezave med spletnim nadlegovanjem in spolom, medtem ko novejše študije potrjujejo, da so dekleta bolj izpostavljena spletnemu nadlegovanju in da spletno nadlegovanje doživljajo drugače kot fantje.

Najobsežnejša študija je bila izvedena $\mathrm{v}$ okviru agencije FRA (European Union Agency for Fundamental rights), kjer je bilo leta 2012 izvedenih 42.000 intervjujev z ženskami iz držav članic EU.

$\mathrm{V}$ raziskavi so ženske spraševali o njihovih izkušnjah s fizičnim, spolnim in psihičnim nasiljem, vključno z nasiljem v družini, od I5. leta dalje. Prav tako so bila vključena vprašanja o zalezovanju, spolnem nadlegovanju in vlogi novih tehnologij pri nadlegovanju in zlorabah.

Da bi ocenili, kolikšen delež jih je doživelo spletno spolno nadlegovanje, sta bili uporabljeni dve spremenljivki in sicer: »neželena spolno eksplicitna e-poštna sporočila ali SMS sporočila« ter »neprimerno 
kontaktiranje/komentiranje na spletnih straneh družbenih omrežij«. Spremenljivki sta bili vključeni v analize kot obliki spletnega nadlegovanja in študija je pokazala, da se je ena od desetih žensk (II \%) soočila z vsaj eno od dveh oblik spletnega nadlegovanja po petnajstem letu starosti, ena od 20 ( $5 \%)$ pa je spletno nadlegovanje doživela v zadnjih dvanajstih mesecih. Ti deleži se zdijo sicer relativno nizki, vendar vključujejo le dve obliki spletnega nadlegovanja, poleg tega pa raziskava kaže, da so mlajša dekleta veliko pogosteje žrtve spletnega nadlegovanja kot ženske, starejše od 30 let. Tako je na primer v starostni skupini $18-29$ let spletno spolno nadlegovanje že doživelo $20 \%$ deklet, v starostni skupini od 30-39 let je spolno spletno nadlegovanje doživelo $13 \%$ respondentk, v skupini 40-49 let II \%, v skupini 50-59 let je bilo takih $6 \%$ in v skupini starejši od 60 let le še $3 \%$ (FRA, 20I2).

Raziskava raziskovalnega centra Pew (2014) je pokazala, da $40 \%$ uporabnikov interneta poroča, da so že doživeli eno od oblik spletnega nadlegovanja, ki je bilo v raziskavi opredeljeno kot zmerjanje, namerno sramotenje, zalezovanje, spolno nadlegovanje, fizične grožnje in stalno nadlegovanje. Študija je pokazala, da je med tistimi, ki so doživeli spletno nadlegovanje, v starostni skupini i8-24 let delež žensk, ki so doživele zalezovanje, spolno nadlegovanje, precej višji, kot je delež moških. Tako je na primer zmerjanje doživelo 51 \% moških in $50 \%$ žensk, sramotenje je doživelo $38 \%$ moških in $36 \%$ žensk, medtem ko je zalezovanje doživelo $7 \%$ moških in $26 \%$ žensk, spolno nadlegovanje pa je doživelo 13 \% moških ter 25 \% žensk (Pew 2014). Lahko rečemo, da mlada dekleta pogosteje doživljajo hude oblike spletnega nadlegovanja.

V projektu deShame (2017) je bila v Veliki Britaniji, na Madžarskem in Danskem izvedena študija o spletnem spolnem nadlegovanju; vključevala je mlade med trinajstim in sedemnajstim let. $V$ študiji je bilo spolno nadlegovanje kategorizirano $\mathrm{v}$ štiri oblike nadlegovanja: a) deljenje intimnih slik ali posnetkov brez privolitve; b) grožnje, izsiljevanje, prisila; c) (seksualizirano) trpinčenje (osebo se trpinči z uporabo spolnih vsebin, ki so ponižujoče); d) prejemanje neželenih spolnih zahtev, komentarjev in vsebin.

Med mladimi iz VB, Madžarske in Danske je bilo $6 \%$ takih, katerih intimne slike ali posnetke so delili, 4I \% pa jih je bila priča takemu deljenju. Kar $68 \%$ anketiranih mladih soglaša, da bi imeli ljudje slabo mnenje o dekletu, čigar gole ali skoraj gole fotografije bi bile objavljene na spletu, medtem ko je delež tistih, ki menijo enako, če bi šlo za fotografije fanta, precej nižji, $40 \%$. Med mladimi je $25 \%$ takih, ki so bili priče, ko je nekdo skrivaj fotografiral osebo (fotografija s spolno vsebino) in fotografijo objavil na internetu, dodatnih to \% pa jih je dejalo, da so to v zadnjem letu storili tudi sami. 
$\mathrm{V}$ zadnjem letu je $9 \%$ anketirancev, starih od 13 do 17 let, na Danskem, Madžarskem in v Veliki Britaniji prejelo grožnje $s$ spolno vsebino od vrstnikov, medtem ko je bilo $29 \%$ vprašanih priča temu. V zadnjem letu so $6 \%$ mladim grozili oziroma jih izsiljevali z njihovimi fotografijami s spolno vsebino. Io \% jih je dejalo, da jih je njihov fant ali dekle $\mathrm{v}$ odnosu prisil/-o, da so se slikali goli, pri čemer se je to večkrat zgodilo dekletom. $25 \%$ anketirancev je dejalo, da je nekdo v zadnjem letu širil govorice o njihovem spolnem vedenju, pri čemer je več kot dve tretjini anketirancev (68\%) dejalo, da so dekleta na podlagi govoric bolj obsojana kot fantje. Med anketiranci je bilo 3I \% takih, ki vedo za nekoga, ki je ustvaril lažni profil, da bi lahko delil fotografije s spolno vsebino. $24 \%$ jih je v zadnjem letu dobilo neželena sporočila in slike s spolno vsebino, pri čemer je delež deklet višji (30 \%) v primerjavi s fanti (I3 \%). Prav tako jih je $24 \%$ dejalo, da so v zadnjem letu prejeli spolne komentarje o fotografiji, ki so jo objavili, pri čemer je verjetnost, da se to zgodi dekletom, večja ( $26 \%)$ v primerjavi s fanti (I8\%). Kar $45 \%$ anketirancev, starih $13-17$ let, je povedalo, da so bili poleg, ko so vrstniki preurejali fotografije nekoga drugega $v$ fotografije s spolno vsebino, ko so urejali fotografije osebe, da bi bile spolne narave, na primer, so njen obraz vstavili v tujo pornografsko sliko.

\section{Spletno nadlegovanje med mladimi v Sloveniji}

Slovenija v pogostosti spletnega nadlegovanja med mladimi ne zaostaja za ostalimi državami. Spomladi $20 r 8$ je bila v okviru projekta Odklikni! i izvedena raziskava o spletnem nadlegovanju med osnovnošolci in srednješolci. Iz zbranih podatkov ugotavljamo, da je več kot polovica $(54,5 \%)$ mladih med I3. in I8. letom že kdaj doživela spletno nadlegovanje, pri čemer so spletno nadlegovanje večkrat doživela dekleta kot fantje.

$\mathrm{V}$ nadaljevanju analiziramo nadaljnje podatke iz raziskave: stališča mladih do spletnega nadlegovanja, ali obstajajo razlike med oblikami spletnega nadlegovanja glede na spol ter kako spletno nadlegovanje doživljajo dekleta in kako fantje.

\section{Metodologija}

V okviru projekta Odklikni! je bila izvedena raziskava o spletnem nasilju med mladimi v Sloveniji. Raziskava je potekala med marcem in aprilom 2018. V raziskavo so bili vključeni osnovnošolci sedmih, osmih in devetih

Projekt Odklikni! izvajata v obdobju 2017-2019 Ministrstvo za delo, družino, socialne zadeve in enake možnosti ter Fakulteta za družbene vede s pridruženimi partnerji (Policija, Ministrstvo za pravosodje). Projekt (CayberVAW - Cyber Violence and Harassment against Women and Girl) naslavlja spletno nasilje in nadlegovanje kot obliki nasilja nad ženskami, ki sta odraz neenakih razmerij moči med ženskami in moškimi. 
razredov ter srednješolci od prvega do četrtega letnika. Raziskava se je izvajala v obliki spletne ankete v vzorcu osnovnih in srednjih šol v celotni Sloveniji, v vseh regijah. Vse šole, vključene v anketo, so bile vzorčene, in sicer za osnovno šolo smo izdelali vzorec roo naključno izbranih šol, pri tem pa smo kontrolirali velikost šole in regijo. $V$ vzorec srednjih šol smo izbrali 50 šol (zavodov, ki večinoma izvajajo več kot en srednješolski program), pri čemer smo upoštevali regijo in program šole.

V raziskavo je bilo vključenih 2991 učenk in učencev osnovne šole ter 2173 srednješolk in srednješolcev.

Zbiranje podatkov je potekalo $\mathrm{z}$ orodjem za spletno anketiranje IKA, na enak način na osnovnih in srednjih šolah. Vprašalnik je poleg osnovnih demografskih vprašanj in vprašanj o rabi interneta in naprav vključeval tudi vprašanja o doživljanju spletnega nadlegovanja, stališčih do spletnega nadlegovanja in iskanju pomoči. Po spletni anketi smo izvedli razprave s šestimi fokusnimi skupinami mladih o rezultatih ankete, spletnem nadlegovanju ter povezanosti spletnega in tradicionalnega nasilja.

\section{Rezultati raziskave Odklikni!}

Rezultati spletne ankete so pokazali, da mladi problematiko spletnega nasilja in nadlegovanja večinoma jemljejo resno, kljub temu pa ugotavljamo, da določenih oblik spletnega nadlegovanja ne prepoznavajo kot nadlegovanje. Pogosto menijo, da so si osebe (predvsem dekleta) same krive, da doživljajo spletno nadlegovanje, fantom pa se pogosto zdi, da je spletno nadlegovanje predvsem (nedolžna) zabava. Ugotavljamo, da so v primeru spletnega nadlegovanja fantje bolj podvrženi družbenemu (vrstniške$\mathrm{mu}$ ) pritisku.

Mladi so stališča o spletnem nadlegovanju ocenjevali na petstopenjski lestvici (sploh se ne strinjam; ne strinjam se; niti se strinjam, niti se ne strinjam; strinjam se; popolnoma se strinjam), ki je bila za potrebe analiz pretvorjena v zaporedne vrednosti od I do 5 (Tabela 2). Tako dekleta kot fantje soglašajo, da se spletno nadlegovanje pogosteje dogaja dekletom, $\mathrm{v}$ povprečju pa s trditvijo najbolj soglašajo srednješolke (povprečje na lestvici je 3,97). Tako fantje kot dekleta bolj soglašajo kot ne s trditvijo, da so dekleta, ki objavljajo svoje fotografije na internetu, sama kriva, da jih nadlegujejo. $S$ trditvijo sicer najbolj soglašajo osnovnošolci (povprečje 3,55) in srednješolci (povprečje 3,52), že omenjeno še višje soglasje zaznamo med dekleti. Rezultat je potrdil razgovor $\mathrm{v}$ fokusnih skupinah, kjer so tako fantje kot dekleta dejali, da »so punce same krive za nadlegovanje, ker objavljajo svoje fotografije «. Prav tako mladi bolj soglašajo, kot ne soglašajo $s$ trditvijo, da je oseba pogosto sama kriva, da jo nadlegujejo. 
B. N. BREČKO - SPLETNO NADLEGOVANJE V ŠOLAH Z VIDIKA SPOLA

Tabela 2: Stališča do spletnega nadlegovanja.

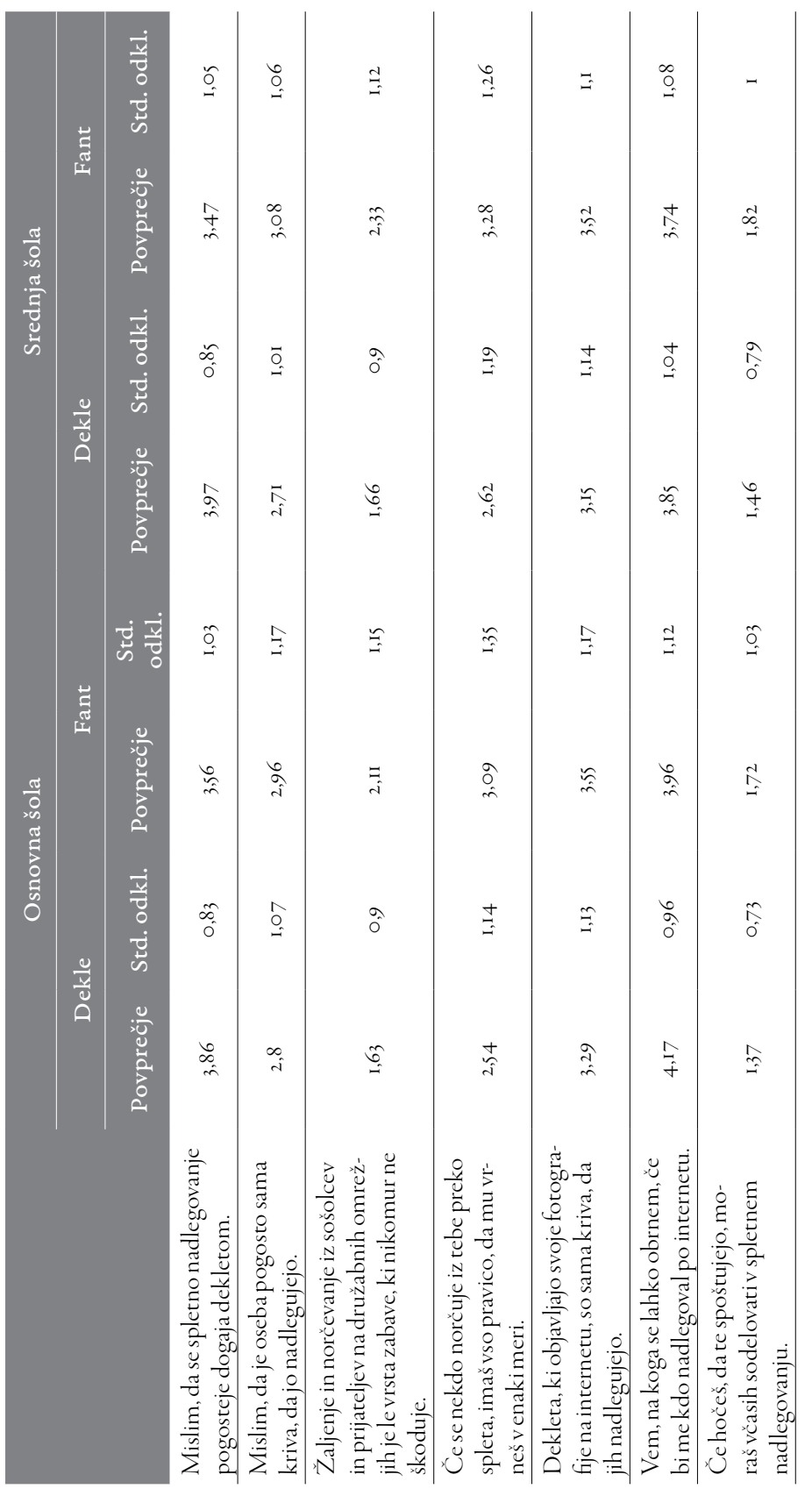

Vir: Odklikni 2oIs. 
Tako fantje kot dekleta večinoma ne soglašajo, da je »žaljenje in norčevanje iz sošolcev in prijateljev na družabnih omrežjih le vrsta zabave, ki nikomur ne škoduje«. Kljub temu so odgovori na vprašanja v nadaljevanju pokazala, da (predvsem fantje) spletno nadlegovanje pogosto razumejo oziroma jemljejo kot vrsto zabave, ki nikomur ne škodi. Zanimiv je bil komentar enega od udeležencev fokusne skupine, ki je dejal, da je seveda na spletu vse le »zafrkancija «, nič ni hudega, ker je nadlegovalec daleč, če pa bi se nadlegovanje oziroma nasilje preneslo v realni svet, pa bi ga bilo strah.

Iz ankete izhaja, da mladi, predvsem osnovnošolska dekleta, vedo, na koga se lahko obrnejo, če bi doživeli nadlegovanje po internetu. Vendar so anketa in razgovori v fokusni skupini pokazali tudi to, da se mladi o spletnem nadlegovanju pogovarjajo predvsem $s$ prijateljicami in prijatelji, $s$ starši in odraslimi na šoli pa v manjši meri.

Podobno, kot kažejo tudi nekatere druge raziskave (npr. deShame 20I8), spletno nadlegovanje pri nas večkrat doživijo dekleta. Med osnovnošolkami je bilo 55,3 \% takih, ki so že doživele vsaj eno od oblik spletnega nadlegovanja, medtem ko je med osnovnošolci delež nižji $(48,6$ \%). Med srednješolkami je delež deklet, ki so že doživele spletno nadlegovanje, zelo visok, 63,9 \%, med srednješolci pa jih je spletno nadlegovanje že doživelo 54,r \%. Gre za visoke deleže mladih, ki so že doživeli spletno nadlegovanje.

Oblike spletnega nadlegovanja so različne, najpogosteje pa mladi, tako fantje kot dekleta, omenjajo širjenje neresničnih govoric. Korelacijska analiza pokaže, da se različne oblike spletnega nadlegovanja pogosto pojavljajo skupaj, torej da mladi doživijo hkrati več kot eno obliko spletnega nadlegovanja.

$\mathrm{V}$ anketi smo mladim navedli različne oblike spletnega nadlegovanja, ti pa so za vsako obliko označili, ali se jim je zgodila ali ne. Deleži predstavljajo odstotek mladih, ki so označili, da se jim je določena oblika nadlegovanja zgodila (deleži se ne seštevajo).

V povprečju dekleta večkrat kot fantje doživijo katero od oblik spletnega nadlegovanja. Kot že omenjeno, je najpogostejša oblika nadlegovanja širjenje neresničnih govoric, tako pri fantih kot tudi dekletih, tako $\mathrm{v}$ OŠ kot tudi SŠ. Med srednješolkami je nekaj manj kot polovica vprašanih že doživela tovrstno nadlegovanje, med osnovnošolkami slabe štiri desetine, medtem ko je pri fantih tako v OŠ kot ŠS okoli tretjina takih, o katerih so širili lažne govorice. Prav tako je pogosta oblika nadlegovanja pošiljanje (oziroma prejemanje) sporočil z neprimerno vsebino - med srednješolkami jih je $38,7 \%$, ki so bile nadlegovane na tak način. Ta oblika nadlegovanja se močno povezuje s prejemanjem fotografij ali videoposnetkov, ki jih 
Tabela 3: Oblike spletnega nadlegovanja.

\begin{tabular}{|c|c|c|c|c|c|c|c|c|}
\hline & \multicolumn{4}{|c|}{ Osnovna šola } & \multicolumn{4}{|c|}{ Srednja šola } \\
\hline & \multicolumn{2}{|c|}{ Dekle } & \multicolumn{2}{|c|}{ Fant } & \multicolumn{2}{|c|}{ Dekle } & \multicolumn{2}{|c|}{ Fant } \\
\hline & $\mathrm{n}$ & $\%$ & $\mathrm{n}$ & $\%$ & $\mathrm{n}$ & $\%$ & $\mathrm{n}$ & $\%$ \\
\hline Grozili so mi. & 175 & $12,5 \%$ & 238 & $16,3 \%$ & 160 & $16,7 \%$ & 227 & $18,4 \%$ \\
\hline $\begin{array}{l}\text { Prejel/-a sem sporočila z ne- } \\
\text { primerno vsebino. }\end{array}$ & 419 & $29,9 \%$ & 337 & $23,1 \%$ & 368 & $38,7 \%$ & 353 & $28,9 \%$ \\
\hline $\begin{array}{l}\text { Šrili so neresnične govori- } \\
\text { ce o meni. }\end{array}$ & 534 & $38,4 \%$ & 422 & $29,0 \%$ & 448 & $47,2 \%$ & 397 & $32,8 \%$ \\
\hline $\begin{array}{l}\text { Delili so moje fotografije ali } \\
\text { video posnetke, ki niso bili } \\
\text { namenjen javnosti. }\end{array}$ & 144 & $10,3 \%$ & 172 & II, $8 \%$ & $\mathrm{I} 23$ & $12,9 \%$ & 175 & $\mathrm{I} 4,4 \%$ \\
\hline $\begin{array}{l}\text { Ustvarjen je bil moj lažni pro- } \\
\text { fil (npr. na Facebooku). }\end{array}$ & 59 & $4,2 \%$ & $8 \mathrm{I}$ & $5,6 \%$ & 65 & $6,8 \%$ & 73 & $6,0 \%$ \\
\hline $\begin{array}{l}\text { Ustvarjena je bila spletna } \\
\text { stran o meni. }\end{array}$ & 25 & $\mathrm{I}, 8 \%$ & 40 & $2,7 \%$ & 23 & $2,4 \%$ & 39 & $3,2 \%$ \\
\hline $\begin{array}{l}\text { Moje slike so bile spremenje- } \\
\text { ne na žaljiv način. }\end{array}$ & 93 & $6,7 \%$ & $\mathrm{II} 3$ & $7,8 \%$ & 84 & $8,8 \%$ & 130 & $10,6 \%$ \\
\hline Izsiljevali so me. & 120 & $8,6 \%$ & 103 & $7,1 \%$ & 85 & $8,9 \%$ & 78 & $6,4 \%$ \\
\hline $\begin{array}{l}\text { Prejel/-a sem žaljive, nesra- } \\
\text { mne komentarje o mojem } \\
\text { videzu. }\end{array}$ & 327 & $23,4 \%$ & 232 & $16,0 \%$ & 229 & $24, \mathrm{I} \%$ & 214 & $17,6 \%$ \\
\hline $\begin{array}{l}\text { Nekdo je na spletu delil skriv- } \\
\text { nost, ki sem jo zaupal/-a le } \\
\text { eni osebi. }\end{array}$ & 106 & $7,6 \%$ & IIO & $7,6 \%$ & 98 & $10,3 \%$ & $8 \mathrm{I}$ & $6,7 \%$ \\
\hline $\begin{array}{l}\text { Dobil/-a sem sporočilo, zara- } \\
\text { di katerega me je bilo strah. }\end{array}$ & 236 & $17,0 \%$ & 150 & $10,4 \%$ & 167 & $17,6 \%$ & I3I & $10,9 \%$ \\
\hline $\begin{array}{l}\text { Nekdo se je delal, da sem jaz, } \\
\text { in naokoli pošiljal sporočila, } \\
\text { zaradi katerih sem izgubil/- } \\
\text {-a prijateljice in prijatelje ter } \\
\text { ugled. }\end{array}$ & 104 & $7,5 \%$ & 100 & $6,9 \%$ & 76 & $8, \circ \%$ & 87 & $7,2 \%$ \\
\hline $\begin{array}{l}\text { Prejel/-a sem fotografije ali } \\
\text { videoposnetke, ki jih nisem } \\
\text { želel/-a videti. }\end{array}$ & 334 & $24,0 \%$ & 219 & $15,2 \%$ & 293 & $31,0 \%$ & $25 \mathrm{I}$ & $20,7 \%$ \\
\hline $\begin{array}{l}\text { Nekdo je na spletu napisal, da } \\
\text { spim z vsemi fanti/dekleti. }\end{array}$ & n.a. & n.a. & n.a. & n.a. & 64 & $6,8 \%$ & 72 & $6,0 \%$ \\
\hline $\begin{array}{l}\text { Nekdo je o meni dajal ko- } \\
\text { mentarje s spolno vsebino. }\end{array}$ & n.a. & n.a. & n.a. & n.a. & IOI & $10,7 \%$ & 108 & $8,9 \%$ \\
\hline $\begin{array}{l}\text { Ni doživel/-a nobene oblike } \\
\text { spletnega nadlegovanja }\end{array}$ & 652 & $44,7 \%$ & 780 & $5 \mathrm{I}, 4 \%$ & 360 & $36,1 \%$ & 593 & $45,9 \%$ \\
\hline
\end{tabular}

\section{Vir: Odklikni 2ors.}

I Osnovnošolci niso odgovarjali na to vprašanje.

2 Osnovnošolci niso odgovarjali na to vprašanje. 
Tabela 4: Prevladujoč občutek ob doživljanju spletnega nadlegovanja.

\begin{tabular}{lcccc} 
& \multicolumn{2}{c}{ Dekle } & Fant \\
\cline { 2 - 5 } Zaskrbljeno & $\mathrm{n}$ & $\%$ & $\mathrm{n}$ & $\%$ \\
\hline Jezno & 436 & $34,9 \%$ & 204 & $16,8 \%$ \\
\hline Stresno & 405 & $32,5 \%$ & 239 & $28,0 \%$ \\
\hline Prestrašeno & 395 & $31,7 \%$ & $16,7 \%$ \\
\hline Razburjeno & 318 & $25,5 \%$ & 144 & $11,9 \%$ \\
\hline Depresivno & 314 & $25,2 \%$ & 212 & $17,5 \%$ \\
\hline Nemočno & 296 & $23,7 \%$ & 160 & $13,2 \%$ \\
\hline Bilo mi je vseeno & 280 & $22,4 \%$ & 136 & $11,2 \%$ \\
\hline Osramočeno & 278 & $22,3 \%$ & 408 & $33,7 \%$ \\
\hline Osamljeno & 256 & $20,5 \%$ & 143 & $11,8 \%$ \\
\hline Nisem mogla/mogel spati & 216 & $17,3 \%$ & 121 & $10,0 \%$ \\
\hline Bilo mi je smešno & 213 & $17,1 \%$ & 87 & $7,2 \%$ \\
\hline Nisem se mogel/mogla učiti & 191 & $15,3 \%$ & 342 & $28,2 \%$ \\
\hline Nadlegovanje ni imelo učinka name & 170 & $13,6 \%$ & 243 & $20,1 \%$ \\
\hline Nisem si upal/a v šolo & $1078,4 \%$ \\
\hline Vedel/a sem da grele za zabavo & $9,5 \%$ & $52 \%$ \\
\hline
\end{tabular}

\section{Vir: Odklikni 20I8.}

oseba ni želela videti ( $\mathrm{r}=0,50 \mathrm{r})$. Nekaj manj kot dve desetini deklet v OŠ in SŠ (I7 \%) je prejelo sporočila, zaradi katerih jih je bilo strah, medtem ko je med fanti takih le desetina. Med srednješolkami jih je ı, 7 \% poročalo, da so že doživele, da je nekdo o njih dajal komentarje s spolno vsebino, med srednješolci pa je ta delež nekoliko nižji. Precejšnjo razliko med spoloma zaznamo pri obliki nadlegovanja »prejel/-a sem žaljive, nesramne komentarje o mojem videzu«, ki se v veliko večji meri dogaja dekletom. Med osnovnošolkami je to doživelo 23,4 \% deklet in med srednješolkami 24,I \%, med fanti pa so deleži nižji, med osnovnošolci je takih I6 \% in med srednješolci $17,4 \%$.

Oblika nadlegovanja, ki pa jo pogosteje doživljajo fantje kot dekleta, je prejemanje groženj, tako pri osnovnošolcih kot srednješolcih.

Nobene oblike nadlegovanja ni doživelo 44,7 \% osnovnošolk in le 36,I \% srednješolk, med fanti pa spletnega nadlegovanja ni doživelo 51,4 \% osnovnošolcev ter $49,5 \%$ srednješolcev. 
Dekleta doživljajo spletno nadlegovanje precej drugače od fantov. Za fante lahko rečemo, da se jim zdi nadlegovanje pogosto način zabave, ga ne jemljejo resno, dekleta pa večinoma doživljajo večje stiske (Tabela 4).

Fantom je ob spletnem nadlegovanju v veliki meri vseeno (33,7 \%), smešno ( $28,2 \%)$, so jezni ( $28 \%$ ), pravijo, da nadlegovanje nanje nima učinka (20,1 \%), oziroma menijo, da gre le za zabavo (17,9\%).

Dekleta pa doživljajo predvsem negativen čustveni odziv. Počutijo se zaskrbljeno (34,9\%), jezno (32,5\%), stresno (31,7 \%), prestrašeno (25,5\%), razburjeno $(25,2 \%)$, depresivno $(23,7 \%)$, nemočno $(22,4 \%)$. Tudi med dekleti je 22,3\% takih, ki so dejala, da jim je bilo ob nadlegovanju vseeno.

\section{Razprava in zaključek}

Mladi so v povezavi s spletnim nadlegovanjem izjemno ranljiva skupina, saj so zelo izpostavljeni tehnologijam in internetu, so zelo pogosti uporabniki družbenih omrežij, kjer se spletno nadlegovanje dogaja najpogosteje. Dekleta so še posebno ranljiva, saj se jim pogosto spletno nadlegovanje dogaja zgolj zato, ker so dekleta.

Spletno spolno nadlegovanje izhaja iz zapletene kombinacije družbenih, vrstniških, partnerskih/intimnih odnosov in razvojnih dejavnikov, ki jih omogoča digitalna tehnologija. (deShame, 2017). Spletno nadlegovanje se dogaja v družbenem kontekstu, kjer razširjena kultura seksualizacije, mizoginije in homofobije pogosto ostaja neobravnavana (Henry in Powell, 2016). Sramotenje (ang. slut shaming) in okrivljanje žrtev nista značilna zgolj za najstnike (Pew Research Center, 20I4) ali za spletno nadlegovanje (npr. Hackman et al., 2017), imata pa ključno vlogo pri tem, kako žrtev doživlja spolno nasilje (meni, da je sam/-a kriv/-a, da se je nasilje zgodilo). Drugi dejavniki, ki lahko pomembno doprinesejo k marginalizaciji mladih, ki doživljajo spletno spolno nadlegovanje, so rasa, etnična pripadnost, invalidnost, spolna identiteta. Pritisk vrstnikov je v tem obdobju velik. Čeprav se mladi večinoma držijo predvidenih družbenih norm in pričakovanih vedenj, pa znotraj mladostniških vrstniških skupin obstajajo norme in vedenja, še posebno v intimnih odnosih, ki so lahko tudi drugačne od siceršnjih družbenih norm. Mladi iščejo potrditev sovrstnikov in v tem lahko podležejo pritisku skupine, ki pa se ne vede v skladu s splošnimi družbenimi normami. Medvrstniški pritisk lahko prispeva $\mathrm{k}$ oblikovanju stališč in vedenja ter normaliziranju potencialno škodljivih vedenj (npr. zgodnja spolna aktivnost, spletno nadlegovanje). Zaznane kršitve pričakovanih normativov lahko povzročijo sramotenje na spletu. Obdobje razvoja v odraslost je v splošnem kritično. Ko mladi prehajajo iz otroštva v odraslost, iščejo nove občutke, raziskujejo spolnost, izpostavljeni so določenim tveganjem. Zaradi dojemljivosti za pritisk vrstnikov ter 
pomanjkanja razumevanja spolnosti in intimnih odnosov pa so izpostavljeni določenim tveganjem (deShame, 2017). Partnerski in intimni odnosi so posebej izpostavljeni. Ko mladi raziskujejo svoje zgodnje spolne interakcije in intimnost, se učijo o privolitvi, spoštovanju in zaupanju. Lahko se zgodi, da prestopijo mejo med spogledovanjem in nadlegovanjem, spodbujanjem in prisilo. Včasih so ta vedenja nasilna, izkoriščevalska in krepijo škodljivo dojemanje spola in spolnosti (deShame, 2017).

Spletno nadlegovanje med mladimi je resen problem, saj ga je vsaj enkrat že doživela približno polovica mladih v Sloveniji, pri čemer je delež deklet, ki so doživele nadlegovanje, višji od deleža fantov. Čeprav se po eni strani kaže, da mladi problematiko spletnega nadlegovanja jemljejo resno, pa po drugi strani ugotavljamo, da lahko govorimo tudi o normalizaciji pojava. Predvsem fantom se zdi spletno nadlegovanje način zabave, ne zdi se jim nič hudega niti, če so nadlegovani, niti, če oni nadlegujejo druge. Kot se je izkazalo v pogovorih v fokusnih skupinah, je morda eden od razlogov za to tudi anonimnost, ki jo nudi splet. Fantom se nadlegovanje pogosto dogaja med igranjem spletnih iger in morda okolje doprinese $\mathrm{k}$ temu, da se jim zdi pojav manj resen in zaskrbljujoč.

Prav tako ugotavljamo, da tako fantje kot dekleta pogosto menijo, da si je žrtev sama kriva, da so jo nadlegovali, ker se je izpostavljala oziroma objavljala svoje fotografije. Ko pride do spletnega nadlegovanja, mladi običajno ne storijo nič ( $31,2 \%$ od vseh) in ignorirajo nadlegovanje ( $27 \%$ od vseh). Dekleta se sicer zaupajo prijateljem ( $30 \%$ med dekleti), nekaj pa se jih zaupa tudi staršem oziroma skrbnikom ( $20 \%$ med dekleti).

Nasilje na osnovi spola je nasilje, ki se človeku zgodi izključno zaradi njegovega spola. Čeprav je fizično nasilje pogosta oblika nasilja na osnovi spola, tudi uradno ni omejeno zgolj na to. Evropski svet opredeljuje nasilje na podlagi spola kot dejanja, ki vodijo $v \gg$ fizično, spolno, psihološko ali ekonomsko škodo ali trpljenje žensk « (https://nobullying.com/gender-violence/). Zagotovo je tudi spletno nasilje ena od oblik nasilja na podlagi spola, ki je med slovenskimi mladostniki zelo prisotna.

Študija Odklikni! je bila prva večja študija s področja spletnega nadlegovanja v Sloveniji. Gre za občutljivo tematiko med mlado populacijo, zato je tovrstno raziskovanje vedno nekoliko tvegano, saj lahko pričakujemo, da bodo respondenti podajali družbeno zaželene odgovore oziroma bodo na vprašanja odgovarjali neresno. Analiza odgovorov je pokazala, da so anketiranci odgovarjali resno in zavzeto, kar je razvidno tudi iz odprtih odgovorov (vprašalnik je vključeval tudi več odprtih vprašanj, kjer so mladi lahko pojasnili svoja mnenja ter podali komentar na anketo). Prav tako so izvedene fokusne skupine pokazale, da so se mladi o tematiki pripravljeni pogovarjati, je pa izredno pomembno, da se med moderatorjem 
in udeleženci fokusne skupine ustvari zaupanje in se ustvari okolje, kjer si udeleženci upajo izraziti svoje mnenje in izkušnje.

O spletnem nasilju je treba govoriti, izobraževati o resnosti posledic, ozavestiti, kaj vse je spletno nasilje. Ravno zato je projekt Odklikni! v prvi vrsti projekt, ki se osredotoča na ozaveščanje in izobraževanje. V okviru projekta je bilo izvedenih več delavnic in izobraževanj. Za mladinske delavce (vse, ki se ukvarjajo z mladimi) sta bila izvedena dva seminarja s i 85 udeleženci, prav tako so bile izvedene delavnice za policijo in pravosodje, (I40 udeležencev). Najpomembnejša populacija pa so mladi, zato je bilo zaenkrat izvedenih že preko ıoo delavnic, na katerih se mladi seznanijo tako $\mathrm{z}$ resnostjo problematike, kot tudi s strategijami, kako se soočiti in ukrepati ob spletnem nadlegovanju.

V okviru projekta nastaja tudi priročnik, katerega namen je opremiti strokovnjake in strokovnjakinje, ki delajo z mladimi, z znanjem in pripomočki za izvajanje delavnic ter pogovorov z mladimi o spletnem nasilju, o posledicah, osveščanju in pomoči žrtvam.

\section{Literatura}

Bauman, S. A., in Bellmore, A. (2015) New Directions in Cyberbullying

Research, Journal of School Violence I 4(I), str. I-IO. https://doi.org/IO.I ○80/15388220.2014.96828I

Belsey, Bill (2003) www.cyberbullying.ca

Bhat, Ch. S. (2008) Cyber Bullying: Overview and Strategies for School Counsellors, Guidance Officers, and All School Personnel [online], Australian Journal of Guidance and Counselling I8(I), str. 53-66 https://search.informit.com.au/documentSummary;dn=6685260967 95989;res=IELHEA

Borgia, L. G., in Myers, J. J. (2oro) Cyber safety and children's literatue: A good match for creating classroom communities, Illinois Reading Council Journal, 38(3), str. 29-34.

Cassidy, W., Jackson, M., Brown, K. (2009) Sticks and stones can break my bones, but how can pixels hurt me? Students' experiences with cyber-bullying, School Psychology International 30, str. 383-402. doi:10.1177/0143034309106948.

Council of Europe (2018) Mapping study on cyberviolence. (Cybercrime Convention Committee (T-CY) Working Group on cyberbullying and other forms of online violence, especially against women and children). https://rm.coe.int/t-cy-2017-IO-cbg-study-provisional/ I6808c49I 4 
deSHAME (2017) Young people's experiences of online sexual harassment. A cross-country report from project deSHAME.

EIGE (2017) Spletno nasilje nad ženskami in dekleti. https://eige.europa.eu/sites/default/files/documents/ti_pubpdf_mho417543sln_ pdfweb_20171026164005.pdf

European Union Agency for Fundamental Rights - FRA (2014) Violence against women: an EU-wide survey http://fra.europa.eu/en/publication/2014/violence-against-women-eu-wide-survey-main-results-report

Hackman, Christine L., Sarah E. Pember, Amanda H. Wilkerson, Wanda Burton in Stuart L. Usdan (2017) Slut-shaming and victim-blaming: a qualitative investigation of undergraduate students' perceptions of sexual violence, Sex Education 17(6), str. 697-71I, DOI: I0.1080/14681811.2017.1362332, https://www.tandfonline.com/doi/ful 1/10.1080/14681811.2017.1362332

Henry, N., Powell, A. (2018) Technology-Facilitated Sexual Violence: A Literature Review of Empirical Research, Trauma, Violence \& Abuse 19(2), str. 195-208. https://doi.org/10.1177/1524838016650189

Hinduja, S., Patchin, J. W. (2012a) Cyberbullying: Neither an epidemic nor a rarity, European Journal of Developmental Psychology 9, str. 539-543. doi:10.1080/17405629.(2012).706448, https://www.tandfonline.com/ doi/full/10.1080/17405629.2012.706448

Hinduja, S., Patchin, J. W. (2012b) School climate 2.o: Preventing cyberbullying and sexting one classroom at a time. Thousand Oaks, CA: Corwin.

Holladay, J. (2011) The Education Digest; Ann Arbor 76(5), str. 4-9.

Kowalski, R. M., Limber, S. P., Agatston, P. W. (2012) Cyberbullying: Bullying in the digital age [2nd ed]. Malden, MA: Wiley-Blackwell.

Law, D. M., Shapka, J. D., Hymel, S., Olson, B. F., in Waterhouse, T. (2012) The changing face of bullying: An empirical comparison between traditional and internet bullying and victimization. Computers in Human Behavior 28, str. 226-232. https://www.sciencedirect.com/ science/article/pii/So74756321100197X

Mark, L., in Ratliffe, K. T. (201 ) Cyber Worlds: New Playgrounds for Bullying, Computers in the Schools, 28(2), str. 92-116, DOI: I0.1080/07380569.2011.575753 https://www.tandfonline.com/doi/full /10.1080/07380569.2011.575753

Mehari, K. R., Farrell, A. D., in Le, A.-T. H. (2014) Cyberbullying among adolescents: Measures in search of a construct, Psychology of Violence, 
4(4), str. 399-415. https://pdfs.semanticscholar.org/oef3/d6d69b6fc0or3forad8a70658a68cc345860.pdf

Odklikni (2018). Baza podatkov.

Patchin, J. W., in Hinduja, S. (2006) Bullies Move Beyond the Schoolyard: A Preliminary Look at Cyberbullying, Youth Violence and Juvenile Justice, 4(2), str. 148-169.

Pew Research Center (2014) Online harassment. https://www.pewresearch. org/wp-content/uploads/sites/9/2014/ro/PI_OnlineHarassment $-72815 \cdot p d f$

Rafferty, R., Vander Ven, Th. (2014) “I Hate Everything About You”: A Qualitative Examination of Cyberbullying and On-Line Aggression in a College Sample, Deviant Behavior 35(5), str. 364-377, DOI: I0.1080/01639625.2013.849171, https://www.tandfonline.com/doi/full /10.1080/01639625.2013.84917I

Raskauskas, J., in Stoltz, A. D. (2007) Involvement in traditional and electronic bullying among adolescents, Developmental Psychology 43(3), str. 564-575. https://pdfs.semanticscholar.org/f 2 Id/b7d If $74 \mathrm{cb}-$ d707e6di68fo4ef9c5be9ree730.pdf

Slonje, R., Smith, P. K., in Frisén, A. (2013) The nature of cyberbullying, and strategies for prevention, Computers in Human Behavior 29(I), str. 26-32. http://dx.doi.org/10.1016/j.chb.2012.05.024

Tokunaga, R. S. (2010) Following you home from school: A critical review and synthesis of research on cyberbullying victimization, Computers in Human Behavior 26(3), str. 277-287. http://www.sciencedirect. com/science/article/pii/So74756320900185X

Valkenburg, P. M., Jochen, P. (20II) Online Communication Among Adolescents: An Integrated Model of Its Attraction, Opportunities, and Risks, Journal of Adolescent Health 48(2), https://www.sciencedirect.com/science/article/abs/pii/Sio54139XI000426X

Wang, J., Iannotti, R. J., in Nansel, T. R. (2009) School bullying among adolescents in the United States: physical, verbal, relational, and cyber. The Journal of adolescent health: official publication of the Society for Adolescent Medicine, 45(4), str. 368-375. doi:10.1016/j.jadohealth.2009.03.02I, https://www.sciencedirect.com/science/article/pii/ SI054139X09001384?via\%3Dihub

West, J. (2014) Cyber-Violence Against Women. Battered Women's Support Services. http://www.bwss.org/wp-content/uploads/2014/05/ CyberVAWReportJessicaWest.pdf

Whittaker, E., in Kowalski, R. M. (2015) Cyberbullying Via Social Media, Journal of School Violence I 4(I), str. II-29, DOI: 
ŠOLSKO POLJE, LETNIK XXX, ŠTEVILKA 3-4

I0.1080/15388220.2014.949377, https://www.tandfonline.com/doi/ful 1/10.1080/15388220.2014.949377

DOI: https://www.doi.org/10.32320/1581-6044.30(3-4)113-130 